\title{
Adherence to the 24-Hour Movement Guidelines among 10- to 17-year-old Canadians
}

\author{
Ian Janssen, PhD (1,2); Karen C. Roberts, MSc (3); Wendy Thompson, MSc (3)
}

This article has been peer reviewed.

\begin{abstract}
Introduction: The Canadian 24-Hour Movement Guidelines for Children and Youth were released in 2016. They contain specific recommendations on the daily time that 5- to 17-year-olds should devote to moderate-to-vigorous physical activity, recreational screen time, and sleep. The objective of this study was to estimate the proportion of Canadians aged 10 to 17 years that meet the recommendations contained within the 24-Hour Movement Guidelines for Children and Youth.
\end{abstract}

Methods: A nationally representative sample of 22115 young people was examined. Movement behaviour data were self-reported. Adherence to the guideline recommendations were based on the following: accumulation of at least 60 minutes per day of moderate-to-vigorous physical activity, no more than 2 hours per day of recreational screen time, and 9 to 11 hours/night of uninterrupted sleep for those aged 10 to 13 years or 8 to 10 hours/night for those aged 14 to 17 years.

Results: Only $3 \%$ of the sample met all three of the key recommendations contained in the guidelines. Twenty-five percent met two of the recommendations, $51 \%$ met one of the recommendations, and $21 \%$ met none of the three recommendations. More children and youth met recommendations for sleep duration (66\%) than for moderate-tovigorous physical activity (35\%) and screen time (8\%).

Conclusion: A small minority $(<3 \%)$ of Canadians aged 10 to 17 years met all three of the key recommendations contained in the 24-Hour Movement Guidelines for Children and Youth.

Keywords: physical activity, screen time, sleep, child, youth

\section{Introduction}

A lack of physical activity, ${ }^{1,2}$ excessive sedentary behaviour, particularly recreational screen time, ${ }^{3,4}$ and insufficient sleep ${ }^{5,6}$ are associated with an assortment of physical, mental, and social health indicators among school-aged children and youth. Canada had separate and distinct public health guidelines for physical activity ${ }^{7}$ and sedentary behaviour. ${ }^{8}$ The U.S. National Sleep Foundation developed sleep duration guidelines, ${ }^{9}$ and within Canada these guidelines were endorsed by pediatric sleep health experts. ${ }^{5}$ The existence of these three distinct guidelines demonstrates that physical activity, sedentary behaviour, and sleep have historically been considered separate and independent from each other. Nonetheless, researchers are beginning to recognize that these three behaviours are codependent and should be considered simultaneously. ${ }^{10-13}$ Because these three behaviours are mutually exclusive and time spent in these behaviours across a day must collectively account for the entire 24-hour period, time spent in physical activity, sedentary behaviour, and sleep are codependent. In other words, time spent in one behaviour necessarily displaces time spent in at least one of the remaining behaviours.

In recognition of the codependence of physical activity, sedentary behaviour, and
Tweet this article

\section{Highlights}

- This study estimated the proportion of Canadians aged 10 to 17 years that meet the recommendations contained within the Canadian 24-hour Movement Guidelines for Children and Youth.

- Only 3\% met all three of the key recommendations for moderate-tovigorous physical activity, screen time, and sleep contained in the guidelines.

- More children and youth met recommendations for sleep duration (66\%) than for moderate-to-vigorous physical activity (35\%) and screen time $(8 \%)$.

sleep, a large group of researchers and knowledge users recently developed the "Canadian 24-Hour Movement Guidelines for Children and Youth: An integration of physical activity, sedentary behaviour and sleep". ${ }^{14}$ Hereafter, these guidelines are referred to as the "24-Hour Movement Guidelines”. The 24-Hour Movement Guidelines were developed under the leadership of the Canadian Society for Exercise Physiology with additional support and endorsement by the Children's Hospital of Eastern Ontario, the Conference Board of Canada, the Public Health Agency of Canada, and ParticipACTION. They contain specific recommendations on the time that 5- to 17-year-olds should devote to moderate-to-vigorous physical activity (MVPA of $\geq 60$ minutes/day), recreational screen time ( $\leq 2$ hours/day), and sleep (9 to 11 hours/day for 5- to 13-year-olds, and 8 to 10 hours/day for 14 - to 17 -yearolds) to support healthy development. Adhering to each of the recommendations within the guidelines is associated with a variety of health outcomes including body

\section{Author references:}

1. School of Kinesiology and Health Studies, Queen's University, Kingston, Ontario, Canada

2. Department of Public Health Sciences, Queen's University, Kingston, Ontario, Canada

3. Public Health Agency of Canada, Ottawa, Ontario, Canada

Correspondence: Ian Janssen, School of Kinesiology and Health Studies, Queen's University, Kingston, ON K7L 3N6; Tel: 613-533-6000 ext. 78631; Email: ian.janssen@queensu.ca 
composition, physical fitness, academic achievement and cognition, emotional regulation, pro-social behaviours, cardiovascular and metabolic health, and overall quality of life. In setting these recommendations, the 24-Hour Movement Guidelines establish measureable targets for surveillance and provide guidance to health-care professionals, researchers, decision makers, and the general public. The 24-Hour Movement Guidelines also highlight to these groups that focusing on a single behaviour is an out-of-date approach, because a person doing well with that behaviour can still have an unhealthy movement behaviour profile. For instance, a child with sufficient MVPA but too much screen time and inadequate sleep does not have an ideal movement behaviour profile.

Now that the new 24-Hour Movement Guidelines have been released, it is important to have timely descriptive information on the proportion of Canadian children and youth who simultaneously achieve all of the movement behaviour recommendations. This information could be used to inform the development of programs and policies to promote healthy movement behaviours. Therefore, the primary objective of this study is to estimate the proportion of Canadian children and youth who simultaneously meet all of the movement behaviour recommendations contained within the 24-Hour Movement Guidelines. The secondary objectives are to estimate the proportion who meet the individual guideline recommendations, as well as the different intermediate combinations of the recommendations (e.g. meet recommendations for physical activity and sleep but not screen time). We had the opportunity to study these objectives using the Health Behaviour in School-Aged Children (HBSC) study, a large and representative sample of Canadians in grades 6 to 10 .

\section{Methods}

\section{Study sample and design}

This study is based on Canadian records from the 2013/14 cycle of the HBSC. The HBSC is a World Health Organization (WHO) collaborative cross-national study of students in grades 6 to $10 . .^{15,} 16$ The 2013/14 Canadian HBSC followed the international sampling protocol. In doing so, classes within 349 schools were selected using a weighted probability technique that ensured proportional representation based on location, language, religion, and community size. Students enrolled in special needs, on-reserve, or non-publicly funded schools were excluded; collectively, they represent $<7 \%$ of young Canadians. ${ }^{16}$ Seventy-seven percent of those originally selected participated, which involved completing a 45-minute long questionnaire. Consent was obtained from students, parents/guardians, individual schools, and school boards. The study received ethics approval from the Queen's University General Research Ethics Board (Research Ethics Committee reference file \#6010236).

The items included in the HBSC questionnaire are continuously developed, validated, and pilot tested by the HBSC international network and in Canada by the Canadian HBSC investigators. ${ }^{15,16}$ In most instances the findings of these validity and pilot studies are not published. However, to comply with the international HBSC protocol, there needs to be evidence that the questionnaire item has acceptable psychometric properties and that it is well-understood by grade 6-10 students.

A small proportion ( $\mathrm{n}=606,2.0 \%$ ) of the original sample of 30153 students completed a condensed questionnaire that did not include the sleep items. An additional 369 (1.2\%) were outside of the target age range (e.g. a grade 12 student taking a grade 10 class). Thus, the eligible sample for the present study consisted of 29178 children and youth aged 10 to 17 years. Of these, $67(0.2 \%)$ were excluded because of missing data on age or gender. An additional 4429 (15.1\%) were excluded because of missing data on one or more of the sleep-time items, or because their weekday and/or weekend sleep duration was greater than three standard deviations from the mean, as we assumed their abnormal data reflected recording errors. An additional 1772 (6.1\%) were excluded because they did not respond to one or more of the physical activity items and 975 (3.3\%) were excluded because they did not respond to one or more of the screen-time items. The final sample size for this study was 22115 . A comparison of the final sample to the 7063 participants that were excluded from the statistical analyses is provided in Table 1 . The relative differences between the included and excluded groups were within $10 \%$ for all of the demographic (e.g. age, gender, race), geographic (e.g. province/territory, municipality size), and movement behaviour (e.g. sleep, MVPA, screen time) variables.

\section{4-Hour Movement Behaviour Guidelines}

The paper describing the 24-Hour Movement Guidelines and their development provides instructions on how these guidelines should be interpreted for surveillance purposes. ${ }^{14}$ These instructions indicate that for minimal inclusion in guideline surveillance, the following three conditions be met: 1) 9 to 11 hours of uninterrupted sleep per night for those aged 5 to 13 years and 8 to 10 hours per night for those aged 14 to 17 years; 2) accumulation of at least 60 minutes per day of MVPA involving a variety of aerobic activities; and 3) no more than 2 hours per day of recreational screen time. The recommendations indicate that each of the aforementioned three conditions should be met when averaging daily time across all 7 days of the week.

\section{Sleep duration}

Participants were asked to report the typical time during the past week that they turned out the lights to go to sleep and woke up in the morning, separately for weekdays and weekends. Based on this information, each participant's average nightly sleep duration was calculated and we determined whether or not participants had a sleep duration that met the recommended range ( 9 to 11 hours/night for 6- to 13-year-olds, and 8 to 10 hours/ night for 14 - to 17 -year-olds). ${ }^{14}$ Sleep durations falling even one minute outside of these ranges were classified as not meeting the guidelines. Results from a validity study indicate that estimates of youths' average nightly sleep duration calculated from self-reported bed times and wake up times are comparable to the average objectively measured sleep duration obtained using actigraphy (471 vs. 461 minutes/night, respectively). ${ }^{17}$

\section{Moderate-to-vigorous physical activity}

Children and youth accumulate their MVPA by participating in physical activities in class time at school (e.g. physical education class), organized sports and programs in their free time, active outdoor play in their free time, and active transportation (e.g. walking or bicycling to school). ${ }^{18}$ The amount of MVPA performed in class time at school and in free time outside of school, including organized sports and programs and active outdoor 
TABLE 1

Descriptive characteristics of 2013/14 HBSC participants according to whether they were included or excluded from the statistical analyses

\begin{tabular}{|c|c|c|c|c|}
\hline \multirow{2}{*}{$\begin{array}{l}\text { Characteristic } \\
\text { Age, mean }\end{array}$} & \multicolumn{2}{|c|}{$\begin{array}{l}\text { Included participants } \\
\qquad \begin{array}{c}(\mathrm{N}=22 \mathrm{115}) \\
\mathrm{n}(95 \% \mathrm{Cl})\end{array}\end{array}$} & \multicolumn{2}{|c|}{$\begin{array}{l}\text { Excluded participants } \\
\qquad \begin{array}{c}(\mathrm{N}=7063) \\
\mathbf{n}(95 \% \mathrm{Cl})\end{array}\end{array}$} \\
\hline & 14.1 & (13.9-14.3) & 14.1 & (13.9-14.3) \\
\hline Gender, \% female & 52.8 & $(51.2-54.5)$ & 45.2 & $(42.7-47.4)$ \\
\hline Race, \% white & 76.0 & (71.6-80.5) & 70.7 & $(65.3-76.0)$ \\
\hline Immigration status, \% born in Canada & 81.3 & (79.2-83.4) & 77.5 & (74.5-80.4) \\
\hline Perceived family wealth, \% not well off & 8.7 & $(8.0-9.3)$ & 9.0 & $(8.0-10.1)$ \\
\hline \multicolumn{5}{|l|}{ Region of Canada } \\
\hline West (BC, AB), \% & 24.7 & $(16.1-33.3)$ & 23.5 & $(13.9-33.2)$ \\
\hline Prairies (SK, MB), \% & 7.8 & $(4.3-11.3)$ & 7.2 & $(3.7-10.7)$ \\
\hline Ontario, $\%$ & 42.8 & $(33.2-52.5)$ & 38.6 & $(28.3-48.9)$ \\
\hline Quebec, \% & 19.1 & $(8.7-29.5)$ & 21.3 & $(10.0-32.6)$ \\
\hline Maritimes (NS, NB, PE), \% & 3.4 & $(1.7-5.1)$ & 7.4 & $(1.2-13.6)$ \\
\hline Territories (NT, YU, NU), \% & 0.5 & $(0.3-0.7)$ & 0.6 & $(0.3-0.8)$ \\
\hline \multicolumn{5}{|l|}{ Type of municipality } \\
\hline Rural (<1000), \% & 4.1 & $(1.2-7.1)$ & 3.3 & $(1.2-5.5)$ \\
\hline Small centre (1000-29 999), \% & 36.7 & $(26.5-46.8)$ & 39.9 & $(28.7-51.0)$ \\
\hline Medium centre (30 000-99 999), \% & 18.7 & $(11.2-26.3)$ & 19.0 & $(10.1-28.0)$ \\
\hline Large centre (100 000-499 999), \% & 25.2 & $(16.9-33.5)$ & 21.8 & $(13.3-30.2)$ \\
\hline Metropolitan ( $\geq 500000), \%$ & 15.3 & $(8.6-22.0)$ & 15.9 & $(7.5-24.4)$ \\
\hline \multicolumn{5}{|l|}{ Movement behaviours } \\
\hline Sleep duration, hours/day & 9.0 & $(8.9-9.0)$ & 9.0 & $(8.9-9.1)$ \\
\hline $\begin{array}{l}\text { Moderate-to-vigorous physical activity, } \\
\text { hours/week }\end{array}$ & 5.6 & $(5.4-5.8)$ & 5.8 & $(5.6-6.1)$ \\
\hline Screen time, hours/day & 7.5 & $(7.3-7.7)$ & 8.1 & $(7.8-8.5)$ \\
\hline
\end{tabular}

Abbreviations: $\mathrm{Cl}$, confidence interval; HBSC, Health-Behaviour in School-Aged Children study.

Note: Data presented as mean $(95 \% \mathrm{Cl})$ for continuous variables and prevalence $(95 \% \mathrm{Cl})$ for categorical variables

play, were assessed with the following two items: "About how many hours a week do you usually take part in physical activity that makes you out of breath or warmer than usual in your class time at school?" and "Outside of school hours: How many hours a week do you usually exercise in your free time so much that you get out of breath or sweat?". Response options to these two items were: "none at all"; "about 1/2 hour"; "about 1 hour"; "about 3 hours"; "about 4 hours"; "about 5 hours"; "about 6 hours" and "about 7 hours". The amount of time spent in active transportation was assessed with the following items: "On a typical day, the main part of your journey to school is made by...." and "How long does it usually take you to travel to school from your home". Participants who did not select the "walking" or "bicycling" options for school travel mode were deemed to have accumulated no active transportation. For those who selected the "walking" or "bicycling" options, their weekly active transportation was determined by multiplying the school travel time by two (to account for trips to and from school) and then by five (as there are five school days/week). We then added time spent in MVPA in active transportation, class time at school, and in free time outside of school, and then divided these times by 7 to obtain their average daily MVPA. Based on this total, participants were categorized into those who did ( $\geq 60$ minutes/day on average) and those who did not ( $<60$ minutes/day on average) meet the MVPA recommendation.
Test-retest reliability analyses indicate there is $\geq 0.80$ agreement between repeated responses to the HBSC active transportation item. ${ }^{19}$ The agreement between repeated responses to the class time at school and free time outside of school physical activity items ranges from $67 \%$ to $85 \%$ across different gender and grade groups. ${ }^{20}$ The test-retest reliability of self-reported organized sport participation is also high $($ Kappa $=0.84) .{ }^{21}$

It is important to note that the recommendation to look at the daily average for MVPA is different from how previous Canadian surveillance studies examined this behaviour, although the recommendation has not changed since the release of the previous physical activity guidelines. Most studies have assessed adherence to the MVPA recommendation based on the achievement of 60 minutes of MVPA on 6 or all 7 days of the week, ${ }^{16,22,23}$ as per Canadian and World Health Organization recommendations at the time of the physical activity guideline release. ${ }^{7,24}$

\section{Screen time}

The amount of time spent watching entertainment on a screen, playing sedentary video games and using electronic screen devices for other purposes were determined using the following items: "How many hours a day, in your free time, do you usually spend watching $\mathrm{TV}$, videos (including YouTube or similar services), DVDs, and other entertainment on a screen?", "How many hours a day, in your free time, do you usually spend playing games on a computer, games console, tablet (like iPad), smartphone or other electronic device (not including moving or fitness games)?" and "How many hours a day, in your free time, do you usually spend using electronic devices such as computers, tablets (like iPad) or smartphones for other purposes (e.g., homework, emailing, tweeting, Facebook, chatting, surfing the internet)?" For each question, the response options were "none at all"; "about half an hour a day"; "about 1 hour a day"; "about 2 hours a day"; "about 3 hours a day"; "about 4 hours a day"; "about 5 hours a day"; "about 6 hours a day"; or "about 7 or more hours a day". Questions were asked for both weekday and weekend use. There is a moderate-tohigh agreement between repeated responses to these HBSC screen-time questions with Kappa coefficients ranging from 0.68 to $0.82 .{ }^{25}$ Average daily screen time was 
calculated and participants were categorized into those who did $(\leq 2.0$ hours/ day) and those who did not ( $>2.0$ hours/ day) meet the screen-time recommendation.

\section{Age and gender categories}

Gender ( $\mathrm{n}=10480$ boys, 11664 girls) and age comparisons were made. For age comparisons, participants were grouped into 10 - to 13-year-olds $(\mathrm{n}=10243$ ) and 14 - to 17 -year-olds ( $n=11901$ ) categories. The cut-point that differentiated the younger and older age groups was selected to correspond with the change in sleep duration recommendations from 13 to 14 years of age. ${ }^{14}$

\section{Statistical analysis}

Statistical analyses were conducted in SAS version 9.4 (Cary, NC, USA). Proc survey procedures with the weight and cluster options were used to account for the sample weights and the clustered (by classroom) nature of the survey. The prevalence of participants adhering to the 24-Hour Movement Guidelines, different intermediate combinations of the guideline recommendations, and different number of guideline recommendations were calculated. Gender and age group differences were determined using the Rao-Scott chisquare test which allowed us to control for clustering at the school level. A $p$-value of $<0.05$ was used to denote statistical significance.

\section{Results}

A description of the sample that was included in the statistical analyses is provided in Table 1. Additional information on the proportion meeting sleep, MVPA, and screen-time recommendations are in Table 2. Of the representative sample of 10to 17 -year-olds studied, $66 \%$ met the sleep duration recommendation, $35 \%$ met the MVPA recommendation, and $8 \%$ met the screen-time recommendation components of the guidelines (Table 2). The proportion of boys and girls meeting the sleep duration recommendation was not different; however, more boys than girls met the recommendation of 60 minutes/day of MVPA. Conversely, more girls than boys met the screen-time recommendation of $\leq 2$ hours /day. The proportion of 10- to 13-year-olds and 14- to 17-year-olds meeting the sleep duration or the MVPA recommendations did not differ; however, a greater proportion
TABLE 2

Proportion of 10- to 17-year-olds that met the individual components of the 24-Hour Movement Guidelines

\begin{tabular}{|c|c|c|c|c|c|}
\hline \multirow[b]{2}{*}{$\begin{array}{l}\text { Guideline } \\
\text { component }\end{array}$} & \multirow[b]{2}{*}{$\begin{array}{l}\text { All participants } \\
\begin{array}{l}(\mathrm{N}=22115) \\
\%(95 \% \mathrm{CI})\end{array}\end{array}$} & \multicolumn{2}{|c|}{ Gender groups } & \multicolumn{2}{|c|}{ Age groups } \\
\hline & & $\begin{array}{c}\text { Boys } \\
(n=10465) \\
\%(95 \% \mathrm{Cl})\end{array}$ & $\begin{array}{c}\text { Girls } \\
(n=11650) \\
\%(95 \% \mathrm{Cl})\end{array}$ & $\begin{array}{c}\text { 10- to } 13 \text {-year-olds } \\
\text { (n =10 236) } \\
\%(95 \% \mathrm{CI})\end{array}$ & $\begin{array}{c}\text { 14- to } 17 \text {-year-olds } \\
\text { (n = 11 879) } \\
\%(95 \% \mathrm{CI})\end{array}$ \\
\hline $\begin{array}{l}\text { Sleep } \\
\text { duration }\end{array}$ & $\begin{array}{c}66.2 \\
(64.7-67.7)\end{array}$ & $\begin{array}{c}65.8 \\
(64.1-67.5)\end{array}$ & $\begin{array}{c}66.6 \\
(64.7-68.5)\end{array}$ & $\begin{array}{c}64.5 \\
(62.4-66.6)\end{array}$ & $\begin{array}{c}67.7 \\
(65.9-69.5)\end{array}$ \\
\hline $\begin{array}{l}\text { Physical } \\
\text { activity }\end{array}$ & $\begin{array}{c}35.4 \\
(32.8-38.0)\end{array}$ & $\begin{array}{c}41.6 \\
(38.7-44.6)\end{array}$ & $\begin{array}{c}29.8 \\
(27.1-32.6)^{*}\end{array}$ & $\begin{array}{c}36.0 \\
(33.7-38.2)\end{array}$ & $\begin{array}{c}34.9 \\
(31.2-38.9)\end{array}$ \\
\hline Screen time & $\begin{array}{c}8.1 \\
(7.1-9.0)\end{array}$ & $\begin{array}{c}7.1 \\
(6.1-8.1)\end{array}$ & $\begin{array}{c}8.9 \\
(7.7-10.1)^{*}\end{array}$ & $\begin{array}{c}11.6 \\
(10.3-12.9)\end{array}$ & $\begin{array}{c}5.0 \\
(4.3-5.8)^{* *}\end{array}$ \\
\hline
\end{tabular}

Abbreviations: 24-Hour Movement Guidelines, Canadian 24-Hour Movement Guidelines for Children and Youth; CI, confidence interval.

Note: Data presented as prevalence $(95 \% \mathrm{Cl})$

${ }^{*}$ Significantly different from boys $(p<0.05)$.

** Significantly different from 10- to 13-year-olds $(p<0.05)$. of 10- to 13-year-olds met the screen-time recommendation.

As shown in Table 3, $21 \%$ of the sample did not meet any of the sleep duration, MVPA, or screen-time recommendations. This proportion was higher in girls than boys but did not differ by age. Approximately $51 \%$ met one of the three recommendations, $25 \%$ met two of the recommendations, and less than $3 \%$ met all three recommendations and adhered to the 24-Hour Movement Guidelines.

Table 4 provides information on the proportion who met different intermediate combinations of the guideline recommendations. Less than $5 \%$ met the recommendations for screen time only, the sleep duration and screen-time combination, and the MVPA and screen time combination. The proportion meeting recommendations for sleep only, MVPA only, and the combination of sleep and MVPA all exceeded $10 \%$.

\section{Discussion}

This study determined the proportion of Canadians aged 10 to 17 years that meet the new 24-Hour Movement Guidelines. A small minority $(<3 \%$ ) met all three of
TABLE 3

Proportion of 10- to 17 -year-olds that met different numbers of the three specific recommendations included in the 24-Hour Movement Guidelines

\begin{tabular}{|c|c|c|c|c|c|}
\hline \multirow{3}{*}{$\begin{array}{l}\# \text { of guideline } \\
\text { recommendations } \\
\text { met }\end{array}$} & \multirow{3}{*}{$\begin{array}{c}\text { All } \\
\text { participants } \\
(\mathrm{N}=22115) \\
\%(95 \% \mathrm{Cl})\end{array}$} & \multicolumn{2}{|c|}{ Gender groups } & \multicolumn{2}{|c|}{ Age groups } \\
\hline & & $\begin{array}{c}\text { Boys } \\
(n=10465)\end{array}$ & $\begin{array}{c}\text { Girls } \\
(\mathrm{n}=11650)\end{array}$ & $\begin{array}{l}\text { 10- to 13-year-olds } \\
(\mathrm{n}=10236)\end{array}$ & $\begin{array}{l}\text { 14- to } 17 \text {-years-olds } \\
(\mathrm{n}=11 \text { 879) }\end{array}$ \\
\hline & & $\%(95 \% \mathrm{Cl})$ & $\%(95 \% \mathrm{Cl})$ & $\%(95 \% \mathrm{Cl})$ & $\%(95 \% \mathrm{Cl})$ \\
\hline None & $\begin{array}{c}20.9 \\
(19.5-22.3)\end{array}$ & $\begin{array}{c}18.8 \\
(17.3-20.4)\end{array}$ & $\begin{array}{c}22.9 \\
(21.1-24.4)^{*}\end{array}$ & $\begin{array}{c}21.2 \\
(19.4-23.0)\end{array}$ & $\begin{array}{c}20.7 \\
(19.0-22.3)\end{array}$ \\
\hline One & $\begin{array}{c}51.1 \\
(49.4-52.9)\end{array}$ & $\begin{array}{c}50.3 \\
(48.5-52.0)\end{array}$ & $\begin{array}{c}51.9 \\
(49.6-54.2)\end{array}$ & $\begin{array}{c}49.3 \\
(47.6-50.9)\end{array}$ & $\begin{array}{c}52.7 \\
(50.4-55.1)^{* *}\end{array}$ \\
\hline Two & $\begin{array}{c}25.3 \\
(23.5-27.2)\end{array}$ & $\begin{array}{c}28.4 \\
(26.1-30.8)\end{array}$ & $\begin{array}{c}22.6 \\
(20.7-24.4)^{*}\end{array}$ & $\begin{array}{c}25.9 \\
(24.2-27.6)\end{array}$ & $\begin{array}{c}24.8 \\
(22.1-27.6)\end{array}$ \\
\hline All three & $\begin{array}{c}2.6 \\
(2.2-3.0)\end{array}$ & $\begin{array}{c}2.5 \\
(2.0-3.0)\end{array}$ & $\begin{array}{c}2.7 \\
(2.2-3.3)\end{array}$ & $\begin{array}{c}3.7 \\
(3.0-4.3)\end{array}$ & $\begin{array}{c}1.7 \\
(1.3-2.2)^{* *}\end{array}$ \\
\hline
\end{tabular}

Abbreviations: 24-Hour Movement Guidelines, Canadian 24-Hour Movement Guidelines for Children and Youth; CI, confidence interval.

Note: Data presented as prevalence $(95 \% \mathrm{Cl})$.

${ }^{*}$ Significantly different from boys $(p<0.05)$.

** Significantly different from 10 - to 13-year-olds $(p<0.05)$. 
TABLE 4

Proportion of 10- to 17-year-olds that met different combinations of the three specific recommendations included in the 24-Hour Movement Guidelines

\begin{tabular}{|c|c|c|c|c|c|}
\hline \multirow{3}{*}{$\begin{array}{l}\text { Combination } \\
\text { of guideline } \\
\text { recommenda- } \\
\text { tions met }\end{array}$} & \multirow{3}{*}{$\begin{array}{c}\text { All } \\
\text { participants } \\
(\mathrm{N}=22115) \\
\%(95 \% \mathrm{Cl})\end{array}$} & \multicolumn{2}{|c|}{ Gender groups } & \multicolumn{2}{|c|}{ Age groups } \\
\hline & & $\begin{array}{c}\text { Boys } \\
(n=10465)\end{array}$ & $\begin{array}{c}\text { Girls } \\
(\mathrm{n}=11650)\end{array}$ & $\begin{array}{c}\text { 10- to 13-year-olds } \\
(\mathrm{n}=10 \text { 236) }\end{array}$ & $\begin{array}{l}\text { 14- to } 17 \text {-years-olds } \\
(\mathrm{n}=11 \text { 879) }\end{array}$ \\
\hline & & $\%(95 \% \mathrm{CI})$ & $\%(95 \% \mathrm{Cl})$ & $\%(95 \% \mathrm{Cl})$ & $\%(95 \% \mathrm{Cl})$ \\
\hline None & $\begin{array}{c}20.9 \\
(19.5-22.3)\end{array}$ & $\begin{array}{c}18.8 \\
(17.3-20.4)\end{array}$ & $\begin{array}{c}22.7 \\
(21.1-24.4)^{*}\end{array}$ & $\begin{array}{c}21.1 \\
(19.4-23.0)\end{array}$ & $\begin{array}{c}20.7 \\
(19.0-22.3)\end{array}$ \\
\hline $\begin{array}{l}\text { Sleep duration } \\
\text { only }\end{array}$ & $\begin{array}{c}39.2 \\
(36.9-41.4)\end{array}$ & $\begin{array}{c}35.9 \\
(33.7-38.1)\end{array}$ & $\begin{array}{c}42.1 \\
(39.2-45.0)^{*}\end{array}$ & $\begin{array}{c}36.1 \\
(34.3-37.9)\end{array}$ & $\begin{array}{c}41.8 \\
(38.6-45.0)^{* *}\end{array}$ \\
\hline $\begin{array}{l}\text { Physical } \\
\text { activity only }\end{array}$ & $\begin{array}{c}10.7 \\
(9.7-11.6)\end{array}$ & $\begin{array}{c}13.2 \\
(12.0-14.4)\end{array}$ & $\begin{array}{c}8.4 \\
(7.3-9.4)^{*}\end{array}$ & $\begin{array}{c}11.4 \\
(10.4-12.5)\end{array}$ & $\begin{array}{c}10.0 \\
(8.7-11.3)\end{array}$ \\
\hline $\begin{array}{l}\text { Screen time } \\
\text { only }\end{array}$ & $\begin{array}{c}1.3 \\
(1.0-1.5)\end{array}$ & $\begin{array}{c}1.1 \\
(0.8-1.4)\end{array}$ & $\begin{array}{c}1.4 \\
(1.1-1.8)\end{array}$ & $\begin{array}{c}1.7 \\
(1.3-2.1)\end{array}$ & $\begin{array}{c}1.0 \\
(0.7-1.2)^{* *}\end{array}$ \\
\hline $\begin{array}{l}\text { Sleep duration } \\
+ \text { physical } \\
\text { activity }\end{array}$ & $\begin{array}{c}21.8 \\
(19.3-23.0)\end{array}$ & $\begin{array}{c}24.9 \\
(22.4-27.3)\end{array}$ & $\begin{array}{c}17.9 \\
(16.1-19.6)^{*}\end{array}$ & $\begin{array}{c}19.6 \\
(18.9-21.3)\end{array}$ & $\begin{array}{c}22.5 \\
(19.8-25.2)^{* *}\end{array}$ \\
\hline $\begin{array}{l}\text { Sleep duration } \\
\text { + screen time }\end{array}$ & $\begin{array}{c}3.2 \\
(2.3-3.7)\end{array}$ & $\begin{array}{c}2.5 \\
(2.0-3.0)\end{array}$ & $\begin{array}{c}3.9 \\
(3.2-4.5)^{*}\end{array}$ & $\begin{array}{c}5.0 \\
(4.3-5.9)\end{array}$ & $\begin{array}{c}1.7 \\
(1.4-2.0)^{* *}\end{array}$ \\
\hline $\begin{array}{l}\text { Physical } \\
\text { activity }+ \\
\text { screen time }\end{array}$ & $\begin{array}{c}0.9 \\
(0.7-1.1)\end{array}$ & $\begin{array}{c}1.0 \\
(0.8-1.3)\end{array}$ & $\begin{array}{c}0.8 \\
(0.6-1.0)\end{array}$ & $\begin{array}{c}1.2 \\
(0.9-1.5)\end{array}$ & $\begin{array}{c}0.7 \\
(0.4-0.9)^{* *}\end{array}$ \\
\hline All three & $\begin{array}{c}2.6 \\
(2.2-3.0)\end{array}$ & $\begin{array}{c}2.5 \\
(2.0-3.0)\end{array}$ & $\begin{array}{c}2.7 \\
(2.2-3.3)\end{array}$ & $\begin{array}{c}3.7 \\
(3.0-4.3)\end{array}$ & $\begin{array}{c}1.7 \\
(1.3-2.2)^{* *}\end{array}$ \\
\hline
\end{tabular}

Abbreviations: 24-Hour Movement Guidelines, Canadian 24-Hour Movement Guidelines for Children and Youth; $\mathrm{Cl}$, confidence interval.

Note: Data presented as prevalence $(95 \% \mathrm{Cl})$.

${ }^{*}$ Significantly different from boys $(p<0.05)$.

** Significantly different from 10 - to 13 -year-olds $(p<0.05)$.

the key recommendations contained in the guidelines. Based on self-reported data, more children and youth meet recommendations for sleep duration (66\%) than for MVPA (35\%) and screen time $(8 \%)$.

The 24-Hour Movement Guidelines have just been released and these are the first public health guidelines that integrate multiple movement behaviours. Therefore, no previous surveillance studies have examined the simultaneous adherence to sleep, physical activity, and screen-time recommendations. Therefore, the results of the present study are novel and they cannot be directly compared to previous studies. With that being said, previous studies based on nationally representative samples of young Canadians have examined adherence to the individual recommendations within the guidelines. Some of these results are discussed below.

The previous Canadian physical activity guidelines for school-aged children and youth recommended 60 minutes of MVPA on a daily basis. ${ }^{7}$ This is identical to the MVPA recommendation contained within the new 24-Hour Movement Guidelines. For surveillance purposes, researchers have historically required that children and youth obtain 60 minutes of MVPA on six or all seven days of the week to be considered physically active. ${ }^{23}$ A paradigm shift in the new 24-Hour Movement Guidelines (and the surveillance recommendations contained within these guidelines) is the notion that for surveillance purposes daily MVPA should be averaged across a week. ${ }^{14}$ Self-reported data from the 2001/02, 2005/06, 2009/10, and 2013/14 cycles of the Canadian HBSC study suggested that $18 \%$ to $20 \%$ of grades 6 to 10 students met the 60 minute target on all seven days of the week. ${ }^{16}$ The shift to an average recognizes that there is day-to-day variability in a young person's MVPA and other movement behaviours, and that ultimately it is more important to accumulate a sufficient volume of MVPA over a week than it is to require that a specific volume of MVPA be accumulated each and every day. ${ }^{1,2}$

Previous Canadian sedentary behaviour guidelines for school-aged children and youth recommended a maximum of 2 hours per day of recreational screen time. ${ }^{26}$ This is identical to the screen-time recommendation contained within the new 24-Hour Movement Guidelines. Previous surveillance studies on screen time in Canada have traditionally considered the average daily screen-time level and did not require the 2-hour target be met on most or all days of the week. That approach is consistent with the surveillance recommendations for screen time that are part of the new 24-Hour Movement Guidelines. ${ }^{14}$ Findings from the $2009 / 10$ cycle of the HBSC indicated that $19 \%$ of grades 6 to 10 Canadians met the screen-time recommendation at that time, ${ }^{16}$ which is twice as high as the $8 \%$ prevalence level reported here based on the 2013/14 HBSC. Substantial changes were made to the questionnaire items that assessed screen time between the 2009/10 and 2013/14 HBSC cycles, which may have in part contributed to the different prevalence estimates. Specifically, the questionnaire items changed to reflect changes to screen-time technology such as the use of tablet computers to watch television programs, inclusion of social media on the computer questions, inclusion of Blu-ray discs in addition to DVDs for movie watching, inclusion of YouTube and similar videos to program watching, and the exclusion of active video games when responding to the video-game question.

There is a limited amount of surveillance data on sleep duration. The only comparable Canadian data that we know of are from the 2012/13 Canadian Health Measures Survey. Findings from that survey suggested that $18 \%$ of 5 - to 11 -year-olds and $33 \%$ of 12 - to 17 -year-olds did not obtain adequate sleep. ${ }^{27}$ Adequate sleep was defined as 10 to 13 hours/day for 5-yearolds, 9 to 11 hours/day for 6- to 13-yearolds, and 8 to 10 hours/night for 14- to 17-year-olds. These findings are similar to those reported here, which suggest that $35 \%$ of 10 - to 13 -year-olds and $32 \%$ of 14- to 17-year-olds did not get the appropriate amount of sleep.

A finding in this paper is that a very small proportion $(<3 \%)$ of Canadians aged 10 to 16 years do well in all of the movement 
behaviours that comprise Canada's new 24-Hour Movement Guidelines for Children and Youth. An important lesson learned is that focusing on a single movement behaviour in isolation does not capture the extent of the movement crisis in young Canadians. For instance, only a third of the sample had a sleep duration that was outside of the recommended range. Nonetheless, it is still valuable to consider the movement behaviours in isolation in addition to their combinations as that provides insights into what specific movement behaviours are the most problematic. In the present study, the screen-time results were particularly concerning as only $8 \%$ of the participants met the screen-time recommendation. Thus, interventions that can successfully reduce screen time may be particularly helpful at improving the movement behaviour profile of young Canadians.

\section{Strengths and limitations}

A key limitation of this study is the selfreported nature of the behavioural data. This could have led to misclassification and over- or underestimated amounts of adherence to the movement behaviour guidelines and its different recommendations. It is also important to note that the assessment of MVPA was limited to activities performed in class time at school, free time outside of school, and active travel to school. Active travel to non-school destinations and activities performed during the school day outside of class time such as recess would not have been captured. Furthermore, the assessment of screen time included homework (as part of the computer use item), even though the $\leq 2$ hour/day screen-time recommendation in the 24-Hour Movement Guidelines is specific to recreational screen time. ${ }^{14}$ The nature of data collection also led to a lot of missing data, as many of the participants chose not to respond to all questionnaire items and/or did not have time to complete all questions. Participants with missing data were excluded from the analyses, and this would have biased the results if the movement behaviours were different in the included and excluded participants. Another limitation was that the sampling strategy excluded youth enrolled in special needs educational programs, those living on reserves, and those not attending publicly funded schools (e.g. homeless youth). Although these groups represent $<7 \%$ of Canadians in the target age range, they are amongst Canada's most vulnerable and their movement behaviours may be different than what was reported here. Additional research is needed in these vulnerable population groups.

\section{Conclusion}

While $79 \%$ of Canadians aged 10 to 17 years met one or more of the three key recommendations that are part of the new Canadian 24-Hour Movement Guidelines, less than $3 \%$ met all three recommendations. Adherence was particularly low for the screen-time and MVPA recommendations. It is hoped that the information from this descriptive study can be used to inform the development of programs and policies to promote healthy movement behaviours in school-aged children and youth.

\section{Acknowledgements}

The 2014 Canadian Health Behaviour in School-Aged Children study and this paper were funded by the Public Health Agency of Canada. IJ was supported by a Canada Research Chair award.

\section{Conflicts of interest}

The authors declare no conflicts of interest.

\section{Authors' contributions and statement}

All authors contributed to the study concept and approved the final version. IJ conducted the statistical analyses and wrote the first draft of the manuscript. KR and WT assisted in the interpretation of results and critically revised the manuscript.

The content and views expressed in this article are those of the authors and do not necessarily reflect those of the Government of Canada.

\section{References}

1. Janssen I, Leblanc AG. Systematic review of the health benefits of physical activity and fitness in school-aged children and youth. Int J Behav Nutr Phys Act. 2010;7(1):40.

2. Poitras V, Gray C, Borghese M, et al. Systematic review of the relationships between physical activity and health indicators in school-aged children and youth. Appl Physiol Nutr Metab. 2016;41(6):S197-S239.
3. LeBlanc AG, Spence J, Carson V, et al. Systematic review of sedentary behaviour and health indicators in the early years (aged 0-4 years). Appl Physiol Nutr Metab. 2012;37:753-72.

4. Carson V, Hunter S, Kuzik N, et al. Systematic review of the relationships between sedentary behaviour and health indicators in school-aged children and youth: an update. Appl Physiol Nutr Metab. 2016;41(6 Suppl 3):S240-S65.

5. Gruber R, Carrey N, Weiss SK, et al. Position statement on pediatric sleep for psychiatrists. J Can Acad Child Adolesc Psychiatry. 2014;23(3):174-95.

6. Chaput JP, Gray C, Poitras V, et al. Systematic review of the relationships between sleep duration and health indicators in school-aged children and youth. Appl Physiol Nutr Metab. 2016;41(6 Suppl 3):S266-S82.

7. Tremblay MS, Warburton DE, Janssen I, et al. New Canadian physical activity guidelines. Appl Physiol Nutr Metab. 2011;36(1):36-46.

8. Tremblay MS, Leblanc AG, Janssen I, et al. Canadian sedentary behaviour guidelines for children and youth. Appl Physiol Nutr Metab. 2011;36(1): 59-64;65-71.

9. Hirshkowitz M, Whiton K, Albert SM, et al. National Sleep Foundation's sleep time duration recommendations: methodology and results summary. Sleep Health. 2015;1:40-3.

10. Chastin SF, Palarea-Albaladejo J, Dontje ML, Skelton DA. Combined effects of time spent in physical activity, sedentary behaviors and sleep on obesity and cardio-metabolic health markers: A novel compositional data analysis approach. Plos One. 2015;10(10):e0139984.

11. Buman MP, Winkler EA, Kurka JM, et al. Reallocating time to sleep, sedentary behaviors, or active behaviors: associations with cardiovascular disease risk biomarkers, NHANES 2005-2006. Am J Epidemiol. 2014;179(3):323-34.

12. Chaput JP, Carson V, Gray CE, Tremblay MS. Importance of all movement behaviors in a 24-hour period for overall health. International journal of environmental research and public health. 2014;11(12):12575-81. 
13. Saunders TJ, Gray CE, Poitras V, et al. Combinations of physical activity, sedentary behaviour and sleep: relationships with health indicators in school-aged children and youth. Appl Physiol Nutr Metab. 2016;41(6 Suppl 3):S283-S93.

14. Tremblay MS, Carson V, Chaput JP, et al. Canadian 24-Hour Movement Guidelines for Children and Youth: an integration of physical activity, sedentary behaviour, and sleep. Appl Physiol Nutr Metab. 2016;41(6 Suppl 3):S311-27.

15. Currie C, Nic Gabhainn S, Godeau E. The Health Behaviour in School-aged Children: WHO Collaborative CrossNational (HBSC) study: origins, concept, history and development 1982-2008. Int J Public Health. 2009; 54 Suppl 2:131-9.

16. Freeman JG, King $M$, Pickett $W$, editors. The Health of Canada's Young People: A Mental Health Focus. Ottawa, ON: Public Health Agency of Canada; 2012.

17. Wolfson AR, Carskadon MA, Acebo $\mathrm{C}$, et al. Evidence for the validity of a sleep habits survey for adolescents. Sleep. 2003;26(2):213-6.

18. Janssen I. Active play: an important physical activity strategy in the fight against childhood obesity. Can J Public Health. 2014;105(1):e22-7.

19. Roberts C, Alexander D, Currie D, Haug E, Komkov A, Tynajala J. Physical activity. Health Behaviour in School-aged Children (HBSC): Research protocol for the 2005/06 survey. Edinburgh: Child and Adolescent Health Research Unit; 2006.

20. Booth ML, Okely AD, Chey T, Bauman A. The reliability and validity of the physical activity questions in the WHO health behaviour in school children (HBSC) survey: a population study. Br J Sports Med. 2001;35(4):263-7.

21. Brener ND, Collins JL, Kann L, Warren CW, Williams BI. Reliability of the Youth Risk Behavior Survey Questionnaire. Am J Epidemiol. 1995; 141(6):575-80.
22. ParticipACTION. The Biggest Risk is Keeping Kids Indoors. The 2015 ParticipACTION Report Card on Physical Activity for Children and Youth. Toronto: PartcipACTION; 2015.

23. Colley RC, Garriguet D, Janssen I, Craig CL, Clarke J, Tremblay MS. Physical activity of Canadian children and youth: accelerometer results from the 2007 to 2009 Canadian Health Measures Survey. Health Rep. 2011; 22(1):15-23

24. World Health Organization (WHO). Global Recommendations on Physical Activity for Health. [Internet]. Geneva (CH): WHO. 2010 [cited]. Available from: www.who.int/dietphysicalactivity /factsheet_recommendations/en/

25. Rey-Lopez JP, Vicente-Rodriguez G, Ortega FB, et al. Sedentary patterns and media availability in European adolescents: The HELENA study. Prev Med. 2010;51(1):50-5.

26. Tremblay MS, Leblanc AG, Janssen I, et al. Canadian sedentary behaviour guidelines for children and youth. Appl Physiol Nutr Metab. 2011;36(1): 59-64.

27. Centre for Chronic Disease Prevention, Public Health Agency of Canada. Chronic Disease and Injury Indicator Framework: Quick Stats, 2015 Edition. Health Promot Chronic Dis Prev Can. 2015;35(10):194-5. 